SCIENTIFIC LETTER

\title{
Efficiency of a minicourse in radiation reducing techniques: a pilot initiative to encourage less irradiating cardiological interventional techniques (ELICIT)
}

\author{
E Kuon, K Empen, D M Robinson, A Pfahlberg, O Gefeller, J B Dahm
}

Heart 2005;91:1221-1222. doi: 10.1136/hrt.2004.048108

$\mathrm{T}$ he reported mean dose-area product (DAP) received by patients from coronary angiography and percutaneous coronary intervention (PCI) is high and typically varies too greatly in invasive cardiology-that is, within 16-106 Gy $\times \mathrm{cm}^{2}$ and 34-109 $\mathrm{Gy} \times \mathrm{cm}^{2}$, respectively. ${ }^{1}$ Skin erythema, chronic radiodermatitis, and musculocutaneous deep injury in conjunction with complex coronary interventions may result. ${ }^{12}$

The International Commission on Radiological Protection points out that, unfortunately, "Many interventionists are not aware of the potential for injury from procedures, their occurrence, or the simple methods for decreasing their incidence utilising dose control strategies". ${ }^{2}$ Recently in clinical routine and with no negative diagnostic implications, effective dose reduction techniques enabled mean patient DAPs of 4.2 (1.6) and 6.7 (5.2) $\mathrm{Gy} \times \mathrm{cm}^{2}$ for elective coronary angiography and one vessel PCI, respectively. ${ }^{13}$

In realisation of the European Directive 97/43 that “Member States shall ensure that practitioners ... have adequate theoretical and practical training for the purpose of radiological practices", ${ }^{4}$ new European guidelines in that field have been established. ${ }^{5}$ We describe the contents of a training minicourse in less irradiating cardiac interventional techniques and its validation in clinical routine.

\section{METHODS}

Before and after the minicourse we analysed the following mean radiation parameters of 10 coronary angiographies, performed by each of the seven participating interventionists at the cardiac centre of Greifswald University, Germany: total $\mathrm{DAP}$, radiographic $\left(\mathrm{DAP}^{\mathrm{R}}\right)$ and fluoroscopic $\left(\mathrm{DAP}^{\mathrm{F}}\right)$ fractions of DAP, the number of radiographic frames and runs, and fluoroscopy time. Bypass graft controls, significant valve diseases, emergency catheterisations, and PCI were excluded, since they are inhomogeneous.

We based our oral in-house PowerPoint minicourse in radiation reducing techniques, 90 minutes in length, on the following recommendations ${ }^{13}$ :

- Restriction to essential radiographic frames

- Consistent systematic use of the low level fluoroscopy mode

- Training of fluoroscopy saving blind positioning to the region of interest

- Restriction to the ostial region of interest during intubation of coronary arteries

- Preference for projections that rotate out the spine

- Adequate, instead of a best possible, image quality

- Full inspiration during radiography if necessary

- Adequately experienced and well rested interventionists.

Images were obtained with a digital, single arm flat panel system (AXIOM Artis dFC; Siemens AG, Erlangen,
Germany). With a focus image detector distance of $1.2 \mathrm{~m}$, a $25 \mathrm{~mm}$ thick aluminium absorber, and a $20 \mathrm{~cm}$ flat panel detector field format, detector entrance dose rates amounted to $0.029 \mu \mathrm{Gy} / \mathrm{pulse}$ ( $15 \mathrm{pulses} / \mathrm{s}$ ) for fluoroscopy and to $0.170 \mu \mathrm{Gy} /$ frame for radiographic documentation (15 frames/s). DAP was measured by a light transparent ionisation chamber (Kl-S Axiom; PTW, Freiburg, Germany).

We based statistical comparison of radiation dose parameters before and after the minicourse on analysis of variance and covariance models (checked by the ShapiroWilks test), which adjusted any mean values for the effect of the interventionist, as well as age, sex, and body mass index of the study patients.

\section{RESULTS}

Patients' mean (SD) overall DAP of all seven interventionists decreased from $30.8(9.8)$ to $19.2(6.8) \mathrm{Gy} \times \mathrm{cm}^{2}(\mathrm{p}<0.001)$ due to a reduction in radiographic $\mathrm{DAP}^{\mathrm{R}}$ from $21.0(6.6)$ to 11.7 (3.2) Gy $\times \mathrm{cm}^{2}(\mathrm{p}<0.001)$.

This was a result of slightly shorter radiographic runs but mainly of the efficient application of radiation reducing tube angulations and a significantly better collimation to the region of interest. $\mathrm{DAP}^{\mathrm{R}} /$ frame decreased from 29.2 (6.9) to 18.4 (4.5) $\mathrm{mGy} \times \mathrm{cm}^{2}(\mathrm{p}<0.001)$ and $\mathrm{DAP}^{\mathrm{F}} / \mathrm{s}$ decreased from 42.5 (11.7) to 26.4 (8.3) $\mathrm{mGy} \times \mathrm{cm}^{2} \quad(\mathrm{p}<0.001)$. However, the latter attempts took time: fluoroscopy time increased slightly from 245 (82) seconds to 266 (101) seconds, so that the reduction of $\mathrm{DAP}^{\mathrm{F}}$ missed significance.

For individual interventionists, the reduction of mean total $\mathrm{DAP}^{\mathrm{R}}$ and $\mathrm{DAP}^{\mathrm{F}}$ was apparently less influenced by the number of radiographic frames and the fluoroscopy time than by the $\mathrm{DAP}^{\mathrm{R}} /$ frame and the $\mathrm{DAP}^{\mathrm{F}} / \mathrm{s}$. Total DAP seems not to depend on the operator's interventional experience (fig l).

\section{DISCUSSION}

The presented minicourse in radiation reducing techniques, the first validated course to date, promises considerably less patient radiation exposure and consequently occupational operator dose due to coronary angiography in clinical routine. That dose reduction predominantly resulted from consistent collimation to the region of interest during both radiography and fluoroscopy.

In this pilot study, mean DAP before and after the minicourse did not correlate with fluoroscopy time, which increased slightly. Moreover, the fact that $\mathrm{DAP}^{\mathrm{R}}$ significantly exceeded $\mathrm{DAP}^{\mathrm{F}}$ raises questions about the widely accepted predominant significance of fluoroscopy time for total patient DAP and the operator's efforts in reducing radiation. ${ }^{12}$

If $\mathrm{DAP}^{\mathrm{F}}$ and $\mathrm{DAP}^{\mathrm{R}}$ are recorded separately, the ratios of $\mathrm{DAP}^{\mathrm{R}} /$ frame to $\mathrm{DAP}^{\mathrm{F}} / \mathrm{s}$ depends on the flat panel detector

Abbreviations: DAP, dose-area product; DAP $\mathrm{P}^{\mathrm{F}}$, dose-area product fluoroscopic fraction; $D A P^{R}$, dose-area product radiographic fraction; $\mathrm{PCl}$, percutaneous coronary intervention 


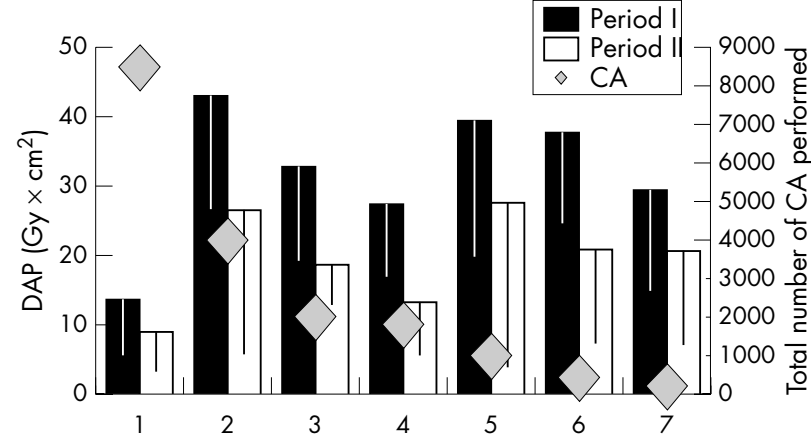

Figure 1 Mean overall dose-area product (DAP) resulting from 10 coronary angiographies for all seven interventionists before (period I) and after (period II) the minicourse in radiation reducing techniques. Doses seem not to depend on the interventionist's experience in performing coronary angiographies (CA, right ordinate).

dose value, which-according to recommended "as low as reasonably achievable" principles ${ }^{2}$ - should be reduced to an adequate, instead of best possible, image quality. For constant detector entrance doses, these parameters vary according to the special requirements of tube angulation. ${ }^{1}$ That is, as recommended in our course programme, interventionists should avoid the typical caudal left anterior oblique spider view for documentation of the left main stem, in favour of the cranial posteroanterior view for its proximal region and caudal posteroanterior view for its distal bifurcation. Similarly, the posteroanterior cranial $0^{\circ} / 30^{\circ}+$ view should be preferred over the cranial left anterior oblique $60^{\circ} / 20^{\circ}+$ view for the bifurcation into the left anterior descending artery and diagonal artery: clinical ${ }^{3}$ and experimental measurements ${ }^{1}$ documented dose reductions of 33$69 \%$ for the patient and in consequence of $60-94 \%$ for the operator. ${ }^{1}$ For identical projections, moreover, the time adjusted DAP fractions indicate the quality of collimation to the region of interest.
In conclusion, the present study definitively confirms that efforts to reduce patient radiation exposure in clinical routine favour both consistent collimation to the region of interest and less irradiating tube angulations. Regular documentation of $\mathrm{DAP}^{\mathrm{F}}$ and $\mathrm{DAP}^{\mathrm{R}}$ and of the number of radiographic frames in addition to fluoroscopy time and total DAP would be well suited to monitor, by self surveillance or by supervisory authorities, each operator's individual long term efforts towards decreasing radiation exposure.

\section{Authors' affiliations}

E Kuon, Department of Cardiology, Klinik Fraenkische Schweiz, Ebermannstadt, Germany

K Empen, D M Robinson, J B Dahm, Department of Internal Medicine, Ernst Moritz Arndt University, Greifswald, Germany

A Pfahlberg, O Gefeller, Institute for Computer Sciences, Biometry and Epidemiology, Friedrich Alexander University, Erlangen-Nuremberg, Germany

Correspondence to: Dr Eberhard Kuon, Klinik Fraenkische Schweiz, Feversteinstrasse 2, D-91320 Ebermannstadt, Germany; eberhard. kuon@klinik-fraenkische-schweiz.de

Accepted 24 November 2004

\section{REFERENCES}

1 Kuon E, Dahm JB, Empen K, et al. Identification of less-irradiating angulations in invasive cardiology. J Am Coll Cardiol 2004;44:1420-8.

2 International Commission on Radiological Protection. Avoidance of radiation injuries from medical interventional procedures. ICRP Publication 85. Ann ICRP 2000;30:9, 16.

3 Kuon E, Glaser C, Dahm JB. Effective techniques to reduce radiation dosage to patients undergoing invasive cardiac procedures. $\mathrm{Br} J$ Radiol 2003;76:406-13.

4 Anon. Council Directive 97/43/Euratom of 30 June 1997 on health protection of individuals against the dangers of ionizing radiation in relation to medical exposure and repealing Directive 84/466/Euratom. Off J Eur Communities 1997; L180:22-7.

5 European Commission. Directorate General-Environment. Guidelines on education and training in radiation protection for medical exposures. Radiation protection 116. 2000. http://europa.eu.int/comm/energy/ nuclear/radioprotection/publication/doc/116_en.pdf (accessed 23 February 2005).

\section{FROM BMJ JOURNALS}

\section{Cost effectiveness of nurse led secondary prevention clinics for coronary heart disease in primary care: follow up of a randomised controlled trial}

Please visit the Heart website [www.heartinl. com] for a link to the full text of this article.

\section{James P Raftery, Guiqing L Yao, Peter Murchie, Neil C Campbell, Lewis D Ritchie}

Objective: To establish the cost effectiveness of nurse led secondary prevention clinics for coronary heart disease based on four years' follow up of a randomised controlled trial.

Design: Cost effectiveness analysis.

Setting: 19 general practices in north east Scotland

Participants: 1343 patients (673 in intervention group and 670 in control group, as originally randomised) aged under 80 years with a diagnosis of coronary heart disease but without terminal illness or dementia and not housebound.

Intervention: Nurse led clinics to promote medical and lifestyle components of secondary prevention.

Main outcome measures: Costs of clinics; overall costs to health service; and cost per life year and per quality adjusted life year (QALY) gained, expressed as incremental gain in intervention group compared with control group.

Results: The cost of the intervention (clinics and drugs) was $£ 136$ (\$254; €195) per patient higher (1998-9 prices) in the intervention group, but the difference in other NHS costs, although lower for the intervention group, was not statistically significant. Overall, 28 fewer deaths occurred in the intervention group leading to a gain in mean life years per patient of 0.110 and of 0.124 QALYs. The incremental cost per life year saved was $£ 1236$ and that per QALY was $£ 1097$.

Conclusion: Nurse led clinics for the secondary prevention of coronary heart disease in primary care seem to be cost effective compared with most interventions in health care, with the main gains in life years saved.

\ $B M J$ 2005;330:707-710. 